\title{
Development of chitosan-coated agar-gelatin particles for probiotic delivery and targeted release in the gastrointestinal tract
}

\author{
Hanady A. Albadran ${ }^{1}$ • Andrea Monteagudo-Mera ${ }^{1}$ - Vitaliy V. Khutoryanskiy ${ }^{2}$. Dimitris Charalampopoulos ${ }^{1}$
}

Received: 19 December 2019 / Revised: 13 April 2020 / Accepted: 17 April 2020 / Published online: 6 May 2020

(C) The Author(s) 2020

\begin{abstract} used for the controlled release of probiotics and potentially other solid bioactives in the large intestine.

Key Points

- Chitosan gel particles is a simple and scalable method of probiotic encapsulation.

- Autoclaving agar-gelatin particles increases their stability at low pH.

- Chitosan gel particles protected L. plantarum during gastrointestinal conditions.

- Probiotics could be controlled release in the colon using chitosan gel particles.
\end{abstract}

This study reports the development of a novel and simple formulation for probiotic delivery using chitosan-coated agar-gelatin gel particles. This methodology involves the production of agar-gelatin particles by thermally treating a mixture of agar and gelatin solutions at high temperatures $\left(121^{\circ} \mathrm{C}\right)$ and subsequently coating with chitosan. The particles were able to protect the probiotic strain Lactobacillus plantarum NCIMB 8826 during incubation for $2 \mathrm{~h}$ in simulated gastric fluid (pH 2), as no statistically significant loss $(P>0.05)$ in cell concentration was observed, and also resist dissolution in simulated intestinal fluid ( $\mathrm{pH}$ 7.2). Interestingly, this protection is related to the fact that the intense thermal treatment affected the physicochemical properties of agars and resulted in the formation of a strong and tight polymer network, as indicated by the X-ray diffraction (XRD) analysis. Using an in vitro faecal batch fermentation model simulating the conditions of the distal part of the large intestine (pH 6.7-6.9), it was demonstrated by quantitative real-time PCR that the majority of L. plantarum cells were released from the agar-gelatin particles within 30 to $48 \mathrm{~h}$. Overall, this work led to the development of a novel methodology for the production of probiotic-containing particles, which is simpler compared with current encapsulation technologies and has a lot of potential to be

Keywords Agar-gelatin $\cdot$ Chitosan $\cdot$ Gel particles $\cdot$ Encapsulation $\cdot$ Probiotic $\cdot$ Faecal fermentation

\section{Introduction}

Agar is a polysaccharide extracted from red seaweeds belonging to the genera of Gelidium spp. and Gracilaria spp. and consists of agarose (1-4)-linked 3,6-anhydro-a-L-galactose

Electronic supplementary material The online version of this article (https://doi.org/10.1007/s00253-020-10632-w) contains supplementary material, which is available to authorized users.

Andrea Monteagudo-Mera

a.monteagudo@reading.ac.uk

1 Department of Food and Nutritional Sciences, University of Reading, Whiteknights, PO Box 226, Reading RG6 6AD, UK

2 Reading School of Pharmacy, University of Reading, Whiteknights, PO Box 224, Reading RG6 6AD, UK alternating with (1-3)-linked B-D-galactose (Saxena et al. 2011). Agar has unique properties, i.e. it gels at $32-39{ }^{\circ} \mathrm{C}$ and melts at $85-95^{\circ} \mathrm{C}$, and has been used for preparing films either on its own (López de Lacey et al. 2014) or in combination with other materials such as milk protein (Letendre et al. 2002), shellac (Phan The et al. 2008), soy protein (Tian et al. 2011), and starch (Wu et al. 2009). Such films can have a variety of applications in the food, pharmaceutical, and cosmetic and personal care sectors. Agar has also been used to develop formulations for the delivery of bioactives in the gastrointestinal tract, more specifically to prepare tablets and microcapsules with gelatin (Lam et al. 2013).

Gelatin is a denatured protein that does not exist in nature, but it is derived from hydrolysed collagen extracted from the skin and bones of bovine or fish (Gómez-Guillén et al. 2002; Chen et al. 2014) and can be either positively charged if extracted with acid or negatively charged if extracted with 
alkaline (Duconseille et al. 2015). Gelatin forms thermally reversible gels with water and has a gel-melting temperature $\left(\sim 40{ }^{\circ} \mathrm{C}\right)$, depending on its concentration. The fact that the electrical and physical properties of gelatin can be altered depending on the processing operations has led to the development of gelatin-based controlled-release systems (Young et al. 2005). Gelatin is also widely used as a material for making hard and soft pharmaceutical capsules (Gullapalli and Mazzitelli 2017).

Probiotics are a group of bacteria described as 'live microorganisms which when administered in adequate amounts confer a health benefit on the host', with the most common commercial bacteria being of the genera Bifidobacterium or Lactobacillus (FAO/WHO 2002). The delivery of probiotics to the gut is often compromised because of their sensitivity to the low $\mathrm{pH}$ of the stomach and the high bile salt conditions of the small intestine (Cook et al. 2012). Encapsulation of probiotics into polysaccharide matrices, such as alginate, usually through an extrusion method, is a viable strategy for the oral delivery of probiotics, as it results in good protection; however, it is difficult to use in large-scale productions owing to the slow formation of the microbeads (Cook et al. 2012; Sarao and Arora 2017). Previously, it was established that probiotic bacteria, such as Lactobacillus and Bifidobacterium strains, encapsulated within calcium alginate beads coated with chitosan, may potentially survive the transit through the harsh environment of the stomach and release high levels of live probiotic in the small intestine (Cook et al. 2011; Cook et al. 2013b; Yeung et al. 2016; Yucel Falco et al. 2019). The protective effect of chitosan coating at high acidic conditions $(\mathrm{pH}<3)$ was found to be due to its ability to delay acid diffusion into the microbeads, whereas the thickness and composition of the coating material influenced the release of the cells at $\mathrm{pH}>6$ (Cook et al. 2013b).

The aim of this work was to develop a novel, simple, and potentially scalable encapsulation method to produce chitosan-coated agar-gelatin particles containing probiotic bacteria, which are able to protect the cells in simulated gastric and small intestine conditions and release the cells in the large intestine. It is envisaged that such method could be used for better management of colonic disorders, such as irritable bowel syndrome and inflammatory bowel diseases.

\section{Materials and methods}

\section{Bacterial strains and growth conditions}

Lactobacillus plantarum NCIMB 8826 was obtained from the National Collection of Industrial and Marine Bacteria (NCIMB), UK. The bacterial strain was cultured at $37{ }^{\circ} \mathrm{C}$ for $16 \mathrm{~h}$ in Man Rogosa and Sharpe (MRS) broth at $200 \mathrm{rpm}$. Cells were harvested by centrifugation at $3200 \mathrm{~g}$ for $15 \mathrm{~min}$. The pellets were washed once using 0.1-M PBS and re-suspended in $10 \mathrm{~mL}$ of PBS, yielding a cell suspension with a concentration of around $\log _{10} 11.5 \mathrm{CFU} / \mathrm{mL}$, determined by the spread plate method using MRS agar ( 2 days of incubation at $37^{\circ} \mathrm{C}$ ).

\section{Preparation and characterisation of bacterial loaded and unloaded agar-gelatin particles}

Agar at different concentrations $(1,1.5,3,4$, and $4.5 \% \mathrm{w} / \mathrm{v})$ and gelatin $(4 \% \mathrm{w} / \mathrm{v})$ were dissolved separately in deionised water, at $70-80^{\circ} \mathrm{C}$ for $2 \mathrm{~h}$. The solutions were mixed at a ratio of $1: 1$, and the mixture was left to cool down to form a gel, or autoclaved at $121^{\circ} \mathrm{C}$ for $15 \mathrm{~min}$ and then left to cool down. For the preparation of unloaded gel particles, $30 \mathrm{~mL}$ of the mixture (autoclaved or non-autoclaved) were poured onto a petri dish, left for $30 \mathrm{~min}$ at room temperature to solidify, and then cut into small particles of around $6 \mathrm{~mm}$. In the case of bacterial loaded gel particles, these were prepared by mixing $1 \mathrm{~mL}$ of cell suspension with $9 \mathrm{~mL}$ of agar-gelatin mixture, and the above procedure followed. The initial cell concentration contained in $1 \mathrm{~g}$ of gel particles (approximately 10 particles) was around $\log _{10} 9.4 \mathrm{CFU} / \mathrm{g}$.

Images of the unloaded gel particles were taken using a digital microscope (LEICA E Z4D), and processed using the ImageJ software to measure the size of the gel particles. Since the shape of the gel particles was regular, the size was determined using the average measurements of 3 diameters, produced from different batches of gel particles.

\section{Coating of agar-gelatin particles with chitosan}

A chitosan solution $(0.4 \% \mathrm{w} / \mathrm{v})$ at $\mathrm{pH} 6.0$ was prepared in 0.1 $\mathrm{M}$ acetic acid. The solution was filtered using a Whatman \#4 filter paper, pasteurised at $72{ }^{\circ} \mathrm{C}$ for $30 \mathrm{~s}$, and cooled down to room temperature. One gramme of loaded gel particles was added into $10 \mathrm{~mL}$ of chitosan solution, and the suspension was stirred for $40 \mathrm{~min}$ at $100 \mathrm{rpm}$. The gel particles were collected by filtration and washed with PBS before use. For bacteria enumeration, $1 \mathrm{~g}$ of gel particles was blended with $99 \mathrm{~mL}$ PBS in a stomacher (model 400 Circulation, Seward, UK) at $300 \mathrm{rpm}$ for $20 \mathrm{~min}$. The suspension was appropriately diluted, spread onto MRS agar plates, and incubated for 2 days at $37{ }^{\circ} \mathrm{C}$. Bacterial colonies were counted and expressed as $\mathrm{CFU} / \mathrm{g}$.

\section{Viability of $L$. plantarum in agar-gelatin particles in simulated gastrointestinal fluids}

Simulated gastric fluid (SGF) was prepared using $0.2 \% \mathrm{w} / \mathrm{v}$ $\mathrm{NaCl}$ and $0.3 \mathrm{~g} / \mathrm{L}$ pepsin, adjusted to $\mathrm{pH} 2$ by adding $1 \mathrm{M} \mathrm{HCl}$. Simulated intestinal fluid (SIF) was prepared using $0.05 \mathrm{M}$ of potassium phosphate buffer $\left(\mathrm{KH}_{2} \mathrm{PO}_{4}\right)(\mathrm{pH} 7.2)$ and $0.125 \mathrm{~g} / \mathrm{L}$ pancreatic lipase. Both SGF and SIF were sterilised using a 
0.2- $\mu \mathrm{m}$ Minisart microfilter (Sartorius Stedim Biotech, Germany). One gramme of gel particles was added to $9 \mathrm{~mL}$ of SGF, and the viability of bacteria was measured after incubation for 60 and $120 \mathrm{~min}$ at $37^{\circ} \mathrm{C}$. Subsequently, after $120 \mathrm{~min}$ in SGF, the gel particles were transferred to $9 \mathrm{~mL}$ of SIF, incubated at $37^{\circ} \mathrm{C}$, and the cell viability measured after 60,120 , and 180 min by the spread plate method using MRS agar.

\section{Faecal batch culture fermentation}

Faecal batch culture fermentations were conducted to study the release of the probiotic in the colon environment. Glass sterile bioreactors $(100 \mathrm{~mL})$ were aseptically filled with $45 \mathrm{~mL}$ of basal medium consisting (per litre) of $2 \mathrm{~g}$ peptone water, $2 \mathrm{~g}$ yeast extract, $0.1 \mathrm{~g} \mathrm{NaCl}, 0.04 \mathrm{~g} \mathrm{~K}_{2} \mathrm{HPO}_{4}, 0.04 \mathrm{~g} \mathrm{KH}_{2} \mathrm{PO}_{4}$, $0.01 \mathrm{~g} \mathrm{MgSO}_{4} \cdot 7 \mathrm{H}_{2} \mathrm{O}, 0.01 \mathrm{~g} \mathrm{CaCl} \cdot 6 \mathrm{H}_{2} \mathrm{O}, 2-\mathrm{g} \mathrm{NaHCO}_{3}, 2 \mathrm{~mL}$ Tween $80,0.05 \mathrm{~g}$ hemin, $0.01 \mathrm{~mL}$ vitamin $\mathrm{K}_{1}, 0.5 \mathrm{~g} / \mathrm{L}$-cysteine- $\mathrm{HCl}, 0.5 \mathrm{~g}$ bile salt, and $4 \mathrm{~mL}$ resazurin solution $(0.25 \mathrm{~g} /$ $\mathrm{L})$. Each vessel was inoculated with $1 \mathrm{~g}$ of agar-gelatin particles (approximately 10 particles) containing $\sim 10^{9} \mathrm{CFU} / \mathrm{g}$ of L. plantarum and $5 \mathrm{~mL}$ of fresh faecal slurry in PBS, obtained by mixing $1 \mathrm{~g}$ of faecal sample from a healthy donor with $10 \mathrm{~mL}$ PBS and homogenisation in a stomacher (model 400 Circulation, Seward, UK) at $300 \mathrm{rpm}$ for $2 \mathrm{~min}$. Donors were healthy and had not received any antibiotic or probiotic treatment for at least 6 months prior to the experiment. Faecal samples were collected in sterile plastic containers which were stored in anaerobic jars containing AnaeroGen sachets (Oxoid, Basingstoke, UK). Stool samples were used within $2 \mathrm{~h}$ of collection.

The fermentation was conducted at $37^{\circ} \mathrm{C}$, controlled using a thermo-circulating water bath, under anaerobic conditions achieved by continuously passing nitrogen though the fermentation system. The $\mathrm{pH}$ was maintained in the range of 6.7-6.9 using a pH control system (Fermac 260, Electrolab, Tewkesbury, UK).

The fermentation was conducted in duplicate using faecal material from two different donors; a third run serving as the negative control was also conducted, using unloaded alginategelatin particles. During the fermentation, the dissolution of the agar-gelatin particles was monitored visually; samples were also collected from the reactor at $0,8,24,48$, and $72 \mathrm{~h}$ and centrifuged at $10,000 \mathrm{~g}$ for $5 \mathrm{~min}$. The cell pellets were resuspended in $50 \%$ glycerol-PBS and kept in $-20{ }^{\circ} \mathrm{C}$ prior to analysis.

\section{Extraction of DNA from faecal samples}

Extraction of DNA from faecal batch culture samples was carried out according to Honda et al. (2011)). Briefly, the cell pellets collected as described in the previous section were washed with $1 \mathrm{~mL}$ PBS and re-suspended in $0.5 \mathrm{~mL}$ TES buffer ( $\mathrm{pH}$ 8). Then, $8 \mu \mathrm{L}$ lysozyme $(10 \mathrm{mg} / \mathrm{mL})$ and $2 \mu \mathrm{L}$ mutanolysin $(1 \mathrm{mg} / \mathrm{mL})$ were added, and then the samples were incubated at $37{ }^{\circ} \mathrm{C}$ for $30 \mathrm{~min}$. Subsequently, $10 \mu \mathrm{L}$ proteinase $\mathrm{K}(20 \mathrm{mg} / \mathrm{mL})$ and $10 \mu \mathrm{L}$ RNase $(10 \mathrm{mg} / \mathrm{mL})$ were added and incubated at $65^{\circ} \mathrm{C}$ for $1 \mathrm{~h} ; 100 \mu \mathrm{L}$ of $10 \%$ sodium dodecyl sulphate were then added, and the samples were incubated for a further $15 \mathrm{~min}$ at $65^{\circ} \mathrm{C}$. In a fume hood, $620 \mu \mathrm{L}$ of phenol/chloroform was added, and the samples were gently mixed by inverting them, for about $2 \mathrm{~min}$. The samples were then centrifuged at $6500 \mathrm{~g}$ for $10 \mathrm{~min}$. DNA was precipitated from the upper aqueous layer with ice-cold ethanol, then the samples were centrifuged at $13,000 \mathrm{~g}$ for $10 \mathrm{~min}$. Supernatants were removed carefully, and the DNA dried before being eluted with $50 \mu \mathrm{L}$ sterile water. The amount $(\mathrm{ng} / \mu \mathrm{L})$ of DNA was quantified by using a ND-1000 NanoDrop spectrophotometer.

\section{Quantitative real-time PCR}

To quantify the levels of $L$. plantarum NCIMB 8826 and validate the release of the cells from the particles into the fermentation medium, primers targeting the plantaricin $\mathrm{EF}$ gene were used (plnEFfw 5'-CTA TTT CAG GTG GCG TTT TC-3' and plnEFrev 5'-GTG GAT GAA TCC TCG GAC AG-3') (Cho et al. 2010a). Plantaricin genes are known to occur only in $L$. plantarum strains, and thus plnEF primers have been used successfully to detect the plnEF gene in a number of studies (Cho et al. 2010b; Cho et al. 2011; Miller et al. 2011). Quantitative real-time polymerase chain reaction (qRT-PCR) was performed using a LightCycler ${ }^{\circledR} 480$ system (Roche, USA). The reaction mixture $(20 \mu \mathrm{L})$ contained $10 \mu \mathrm{L}$ of IQ SYBR green PCR supermix (Bio-Rad), $2 \mu \mathrm{L}$ of the DNA template, and $200 \mathrm{nM}$ of each primer. qRT-PCR reactions were performed in triplicate under the following conditions: initial denaturation at $95{ }^{\circ} \mathrm{C}$ for $10 \mathrm{~min}$, followed by 40 cycles of denaturation at $95{ }^{\circ} \mathrm{C}$ for $10 \mathrm{~s}$, annealing at $54{ }^{\circ} \mathrm{C}$ for $30 \mathrm{~s}$, and extension at $72{ }^{\circ} \mathrm{C}$ for $30 \mathrm{~s}$. A melting curve analysis was done subsequently to determine the specificity of the PCR reaction by denaturing from 55 to $94{ }^{\circ} \mathrm{C}$, immediately after the last cycle of each amplification. The PCR reaction efficiency $\left(\mathrm{E}=10^{1 /-S_{-}}\right.$, where $S=$ slope $)$ was calculated from the log-linear part of a standard curve (Klein et al. 1999).

\section{X-ray diffraction analysis}

Suspensions of solids made from $3 \%(\mathrm{w} / \mathrm{v})$ agar, $4 \%(\mathrm{w} / \mathrm{v})$ gelatin, and agar-gelatin 1:1 mixture (without cells) were analysed before and after autoclaving using an X-ray Bruker D8 Advance Powder diffractometer with copper source and wavelength of $1.54^{\circ} \mathrm{A}$. The samples were analysed between $2 \theta$ from 5 to $70^{\circ}$, with an angle size of $0.007^{\circ}$ at $1 \mathrm{~s}$ per step. 
Data were processed using the Bruker EVA evaluation software package.

\section{Statistical analysis}

The results are reported throughout as mean \pm standard deviation. Statistical analysis of the data was conducted using ANOVA, version. 17 of SPSS. $P$ values $<0.05$ were considered statistically significant.

\section{Results}

\section{Development of agar-gelatin particles and evaluation of their solubility in simulated gastric fluid}

Initial experiments investigated the effect of agar (4.5, $4,3,1.5$, and $1 \% \mathrm{w} / \mathrm{v})$ and gelatin $(3 \% \mathrm{w} / \mathrm{v})$ concentrations as well as autoclaving of the mixture at $121{ }^{\circ} \mathrm{C}$ for $15 \mathrm{~min}$ on the dissolution of the produced agargelatin particles after incubation in SGF for up to $120 \mathrm{~min}$. In all cases, the gel particles $(\sim 6 \mathrm{~mm})$ did not dissolve in SGF after $120 \mathrm{~min}$, and based on the fact that with a higher agar concentration the particles had a more consistent spherical shape (Supplementary Fig. S1), 3\% agar and 4\% gelatin solution were selected for subsequent experiments, as this would most likely facilitate better coating with chitosan and thus enhance the stability of the probiotic.

In order to evaluate the effect of autoclaving on the stability of the agar-gelatin particles in SGF, gel particles $(\sim 6 \mathrm{~mm})$ were also produced by mixing $3 \%$ agar and $4 \%$ gelatin solutions without autoclaving the mixture in this case. Interestingly, upon immersing these particles in SGF, they disintegrated instantly as shown by the noticeable size

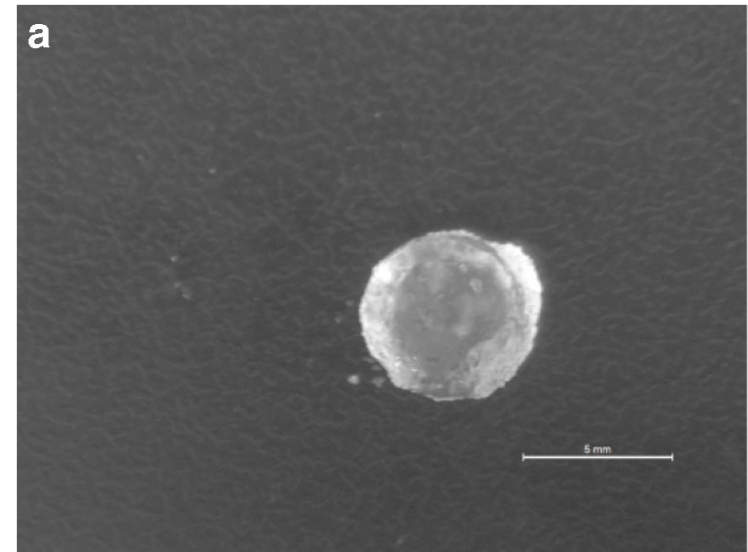

Fig. 1 Images of agar-gelatin gel particles, prepared by mixing agar solution $(3 \% \mathrm{w} / \mathrm{v})$ with gelatin solution $(4 \% \mathrm{w} / \mathrm{v})$ at a ratio of $1: 1$, and then cooling the mixture at room temperature. a Gel particles. b Gel particles decrease (Fig. 1), indicating that the autoclaving step positively influenced the stability of the agar-gelatin particles in SGF and prevented their dissolution.

\section{Viability of $L$. plantarum entrapped in uncoated and chitosan-coated agar-gelatin particles and release profile in simulated gastrointestinal fluids}

Bacterial loaded agar-gelatin particles were produced and used as such or after coating with chitosan, in order to evaluate the cell viability and the release profile after exposure to SGF (up to $120 \mathrm{~min}$ ) and subsequently to SIF (up to $180 \mathrm{~min}$ ). In SGF (Fig. 2a), it can be observed that the gel particles without chitosan coating contained initially $9.50 \pm 0.11 \log \mathrm{CFU} / \mathrm{g}$, whereas chitosan-coated particles contained $9.25 \pm 0.07 \mathrm{log}$ $\mathrm{CFU} / \mathrm{g}$. The viability of $L$. plantarum cells in uncoated gel particles decreased significantly $(P<0.05)$ (to $\sim 4.5 \mathrm{log}$ $\mathrm{CFU} / \mathrm{g}$ ) in SGF after $1 \mathrm{~h}$, whereas after $2 \mathrm{~h}$, no viable cells were detected in $(<2 \log \mathrm{CFU} / \mathrm{g})$. In contrast, the viability of the cells in chitosan-coated particles did not change significantly $(P>0.05)$ with time, and after $2 \mathrm{~h}$, approximately 9.2 $\log \mathrm{CFU} / \mathrm{g}$ was present. Following 2-h exposure in SGF, the chitosan-coated gel particles were placed in SIF for $3 \mathrm{~h}$ (Fig. $2 \mathrm{~b}$ ), and the results showed that the cell viability did not change significantly $(P>0.05)$, and after $3 \mathrm{~h}$, approximately $9.1 \log \mathrm{CFU} / \mathrm{g}$ was present, indicating that the agar-gelatin particles did not disintegrate in SIF.

\section{XRD analysis}

X-ray diffraction (XRD) analysis of the 3\% w/v agar solution and the $4 \% \mathrm{w} / \mathrm{v}$ gelatin solution and their 1:1 mixture was conducted both without autoclaving the solutions and after autoclaving at $121{ }^{\circ} \mathrm{C}$ for $15 \mathrm{~min}$ (Fig. 3). In the case of agar

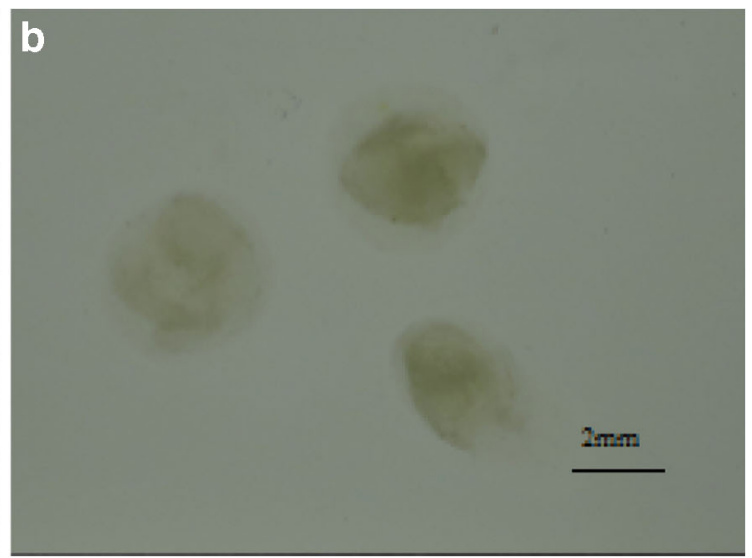

immediately after immersion in simulated gastric fluid (SGF). The scale shown in $\mathbf{a}$ is $5 \mathrm{~mm}$, whereas in $\mathbf{b}$ is $2 \mathrm{~mm}$ 
a

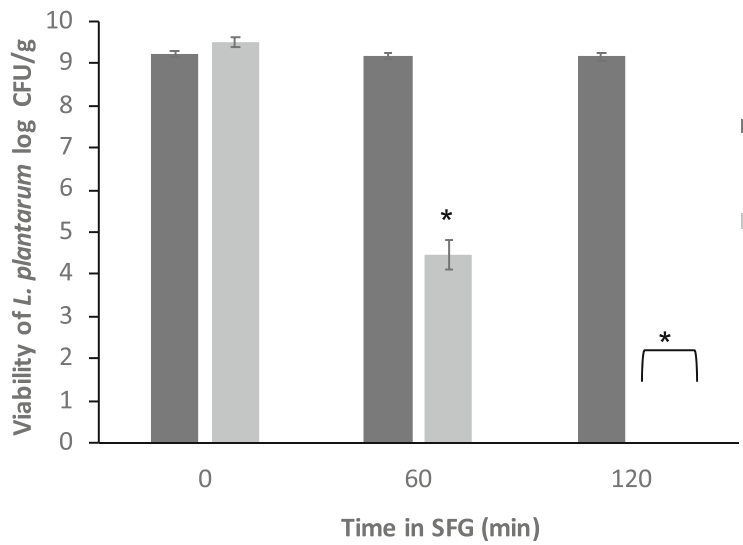

Fig. 2 Viability of L. plantarum entrapped in uncoated and chitosancoated gel particles, prepared by mixing and autoclaving $3 \%$ agar and $4 \%$ gelatin solutions, during incubation in simulated gastric fluid (SGF) for $2 \mathrm{~h}$ (a) and simulated intestinal fluid (SIF) for $3 \mathrm{~h}$ (b). Results are

with no autoclaving (Fig. 3a), the agar gel gave a distinctive peak at $2 \theta=27.9^{\circ}$ and a secondary one at $2 \theta=39.8^{\circ}$. After autoclaving, the predominant peak changed to $2 \theta=23.7^{\circ}$, whereas the second peak disappeared. The insert photographs show that the agar without autoclaving was in a suspension form (semi-solid), whereas after autoclaving and cooling down (at room temperature for $30 \mathrm{~min}$ ), it formed a gel. Gelatin without autoclaving exhibited two peaks of very low intensity (Fig. 3b), one at $2 \theta=28.4^{\circ}$ and a minor one at $39.8^{\circ}$, b

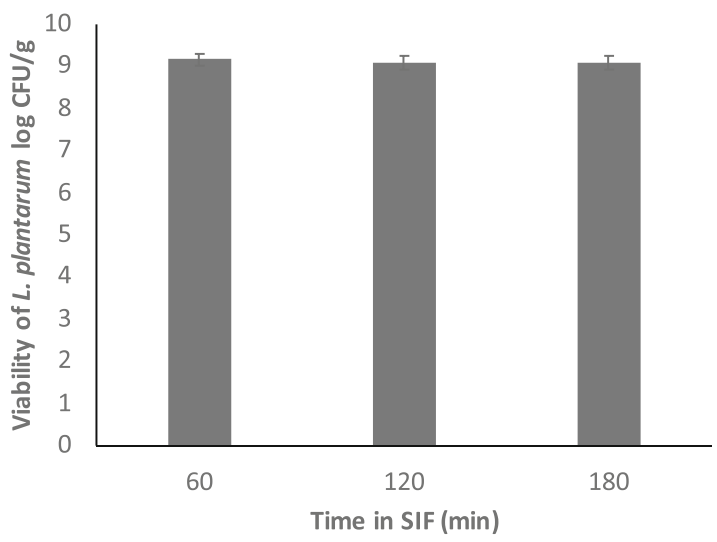

expressed as mean \pm standard deviation $(n=3)$. No viable cells were detected in SGF after $2 \mathrm{~h}$ for uncoated gel particles (cell concentration $<2 \log \mathrm{CFU} / \mathrm{mL})$. * indicates significant difference $(P<0.05)$ compared with the starting point (time 0 )

whereas after autoclaving, it exhibited only one peak, of considerably higher intensity than the non-autoclaved sample, at $2 \theta=25.1^{\circ}$. The insert photographs show that the gelatin without autoclaving behaved as a gel. After autoclaving, the gelatin was cooled down to room temperature for $30 \mathrm{~min}$ and behaved as a liquid, whereas when cooled down to $4{ }^{\circ} \mathrm{C}$, it behaved as a semi-solid.

When agar and gelatin were mixed together (Fig. 3c), the mixture without autoclaving consisted of a single peak at $2 \theta=$
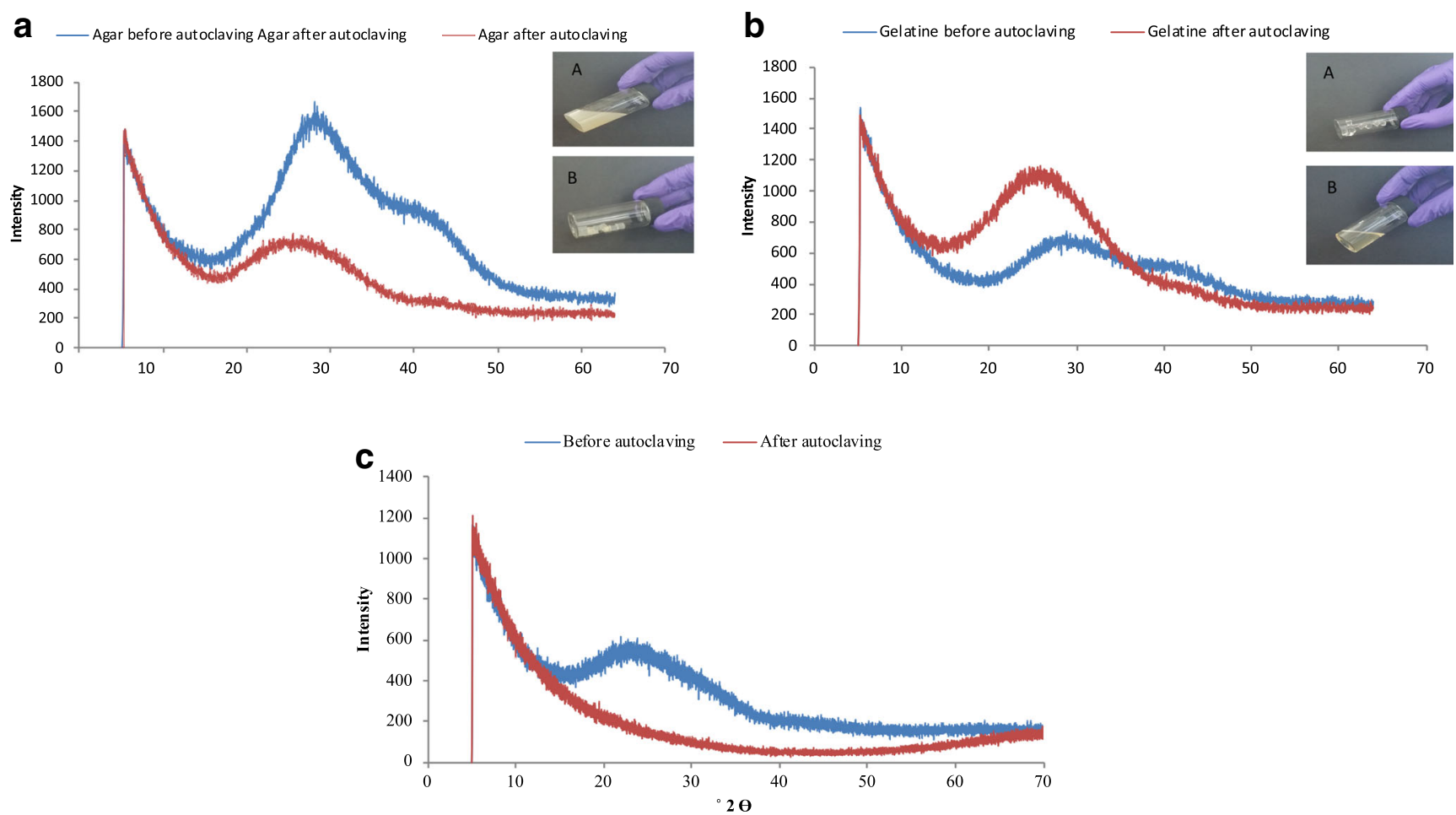

Fig. 3 X-Ray diffraction patterns of a agar suspension (3\% w/v) before and after autoclaving, b gelatin suspension (4\% w/v) before and after autoclaving, and $\mathbf{c}$ agar-gelatin mixture (produced from mixing $3 \% \mathrm{w} / \mathrm{v}$ agar and $4 \% \mathrm{w} / \mathrm{v}$ gelatin at a ratio of 1:1) before and after autoclaving 
$22.5^{\circ}$ of relatively low intensity, whereas after autoclaving, no peak was detected. The insert pictures demonstrate that the mixture without autoclaving behaved as a semi-solid, whereas after autoclaving and cooling down, it behaved as a solid.

\section{Viability of $L$. plantarum entrapped in agar-gelatin particles and release profile in faecal batch culture fermentation}

Unloaded and were added in a faecal batch fermentation system reflecting the physiological conditions of the distal part of the large intestine. The dissolution of the particles was monitored by visual observation, and the concentration of L. plantarum in the fermentation medium was quantified by using qRT-PCR. Figure 4 shows the changes in the size of the loaded and unloaded particles after 8, 24, 30, 48, 72, and $96 \mathrm{~h}$. It can be observed that both loaded and unloaded particles dissolved during faecal fermentation, although the dissolution of the loaded particles was much faster (between 30 and $48 \mathrm{~h}$ ) compared with the unloaded particles ( 72 to $96 \mathrm{~h}$ ).

In order to verify the results from the visual observations, the changes in the concentration of total lactobacilli was measured by using qRT-PCR, using primers targeting the plantaricin EF gene, which is present in L. plantarum. To achieve quantification, a qRT-PCR standard curve relating viable cell counts to qRT-PCR signals was initially constructed using a pure L. plantarum culture. The correlation between the $\mathrm{Ct}$ (cycle threshold) value and the CFUs was highly linear; the slope of the qRT-PCR-generated standard curve equation was -1.715 with a correlation coefficient of 0.99 . The PCR reaction efficiency calculated from the log-linear part of the standard curve was 0.8. The amplification specificity of the qRT-PCR reaction with the plnEF primers was also investigated by using the melting curve analysis of the qRT-PCR products after the final amplification step. Using the melting curve analyses, no non-specific peaks could be detected in the reaction. In addition, no peak was obtained in the no-template control, indicating that neither primer pair dimers nor

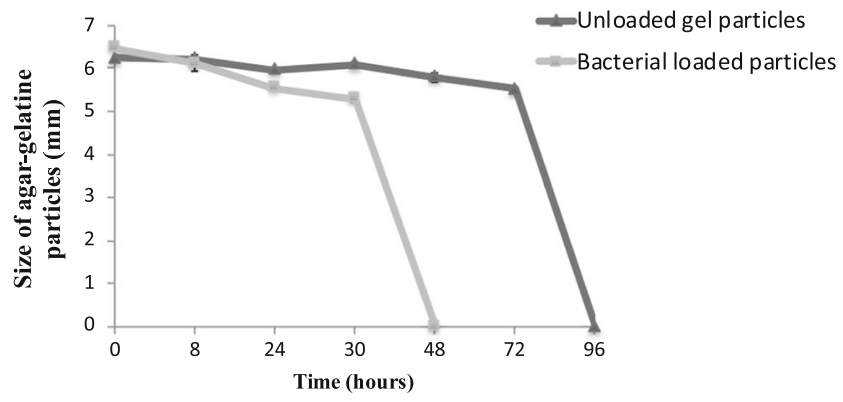

Fig. 4 Changes in size of unloaded and L. plantarum-loaded particles during faecal batch culture fermentation. The particles were prepared by mixing agar solution $(3 \% \mathrm{w} / \mathrm{v})$ with gelatin solution $(4 \% \mathrm{w} / \mathrm{v})$ at a ratio of $1: 1$, and then cooling the mixture at room temperature

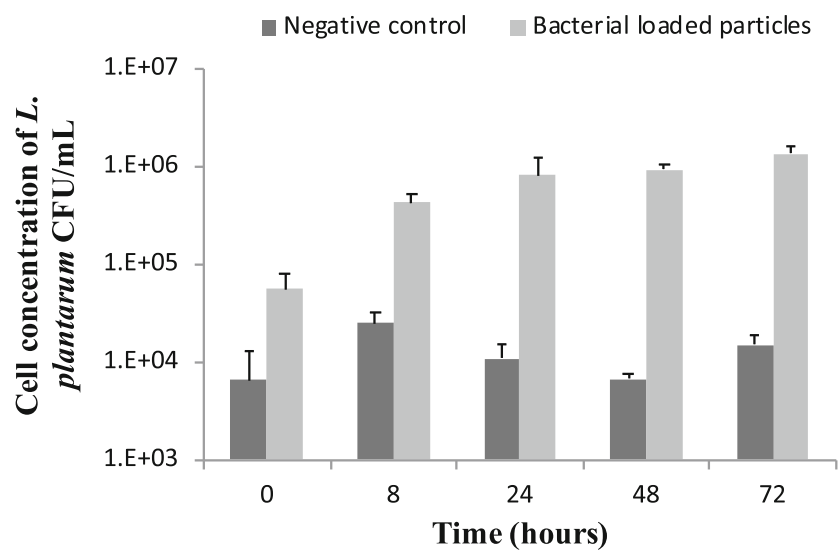

Fig. 5 Cell concentration of $L$. plantarum, determined by using qRTPCR, during batch culture faecal fermentation in the absence and presence of $L$. plantarum-loaded agar-gelatin particles $(1 \mathrm{~g}$ of particles in $50 \mathrm{~mL}$ of fermentation culture). Error bars represent standard deviations from three replicate measurements

unspecific PCR products interfered with the qRT-PCR reaction (data not shown).

The results (Fig. 5) indicated that the majority of L. plantarum cells was released from the agar-gelatin particles within $48 \mathrm{~h}$ of incubation, with the initial cell concentration at time $0 \mathrm{~h}$ (immediately after immersion of the particles into the medium) being $5.6 \times 10^{4} \mathrm{CFU} / \mathrm{mL}$ and increasing to $9.3 \times 10^{5}$ and $1.3 \times 10^{6}$ after 48 and $72 \mathrm{~h}$, respectively. In the case of the negative control (faecal fermentation with no bacterial loaded particles), no significant changes were observed over the whole time course.

\section{Discussion}

The study aimed to develop agar-gelatin particles, with and without coating with chitosan, containing probiotic bacteria to protect the cells in gastric conditions and release the cells in the large intestine rather than in the small intestine. The positive effect that autoclaving had on the stability of the produced agar-gelatin particles in SGF indicated the formation of a strong and tight polymer network. The intense thermal treatment of autoclaving compared with mild heat treatment affected the physicochemical properties of agar, as indicated by the XRD analysis. This was likely due to hydrogen bonding between the molecules inside the double-helical structure of agar that increases the strength of the gel, and therefore, a certain level of crystallisation could be present, as also demonstrated previously ( $\mathrm{Wu}$ et al. 2009). On the other hand, autoclaving of gelatin most likely led to the decrease in $\mathrm{OH}^{-}$ bonding inside the triple-helical structure of gelatin, which caused its denaturation, thus producing an extremely weak gel (Brodsky and Ramshaw 1997), a hypothesis that is supported by the XRD results. The strong gel formed after autoclaving the mixture of agar-gelatin is reflected by the 
disappearance of all peaks in the diffraction graphs. Overall, these results are in agreement with previous research which has shown that a strong correlation generally exists between the strength of the gel and a diffraction pattern with no or low intensity peaks (Cheng et al. 2003; Zhai et al. 2004).

Although the agar-gelatin particles did not disintegrate in SGF, they did not protect the bacterial cells, indicating that acids were able to penetrate inside the core of the particles and kill the cells. The protection provided to the cells by chitosan coating on the agar-gelatin particles is attributed to the strong interaction between chitosan and gelatin, which takes place at $\mathrm{pH} \mathrm{7,} \mathrm{the} \mathrm{pH}$ of the chitosan solution. At $\mathrm{pH} 7$, chitosan is positively charged and it interacts strongly with gelatin, which is negatively charged (Prata and Grosso 2015). To this end, Cheng et al. (2003) carried out X-ray diffraction analysis of mixtures of chitosan and gelatin at different concentrations and found that the crystallisation of the mixture decreased and the gelatinisation increased with increasing the amount of chitosan, as a result of the strong interactions between the $\mathrm{NH}_{3}{ }^{+}$group in chitosan and the $\mathrm{COO}^{-}$group in gelatin. Several researchers have demonstrated that chitosan coating of microcapsules, where the core material is another negatively charged polymer such as alginate, can protect probiotic cells in simulated gastric fluid (Krasaekoopt et al. 2004; Nualkaekul et al. 2012). In the mechanistic study by Cook et al. (2013a), a novel confocal laser-scanning microscopy (CLSM) method was developed for visualising $\mathrm{pH}$ changes within polymer matrices, which led to the generation of ' $\mathrm{pH}$ maps' showing the distribution of $\mathrm{pH}$ within the coated microcapsules. The maps revealed that the protection offered by the chitosan coating layer was due to a combination of buffering effect, which was seen to increase after coating with the basic chitosan, and an encroaching of low $\mathrm{pH}$ from the periphery of the microcapsule into the matrix rather than a bulk $\mathrm{pH}$ change, which was seen in the case of chitosan coating. It is likely that a similar mechanism was used in the case of the chitosan-coated agar-gelatin particles in SGF ( $\mathrm{pH} 2)$, which would explain why the uncoated agar-gelatin particles did not protect sufficiently the cells, although confocal microscopy studies are needed to verify this.

The chitosan-coated agar-gelatin particles provided excellent protection to the cells during the 3-h exposure in SIF, which is of physiological relevance to an in vivo situation, and most interestingly, they did not disintegrate during this period. This is in contrast to what was observed in the case of coated and uncoated alginate microcapsules in previous research from our research group (Cook et al. 2011; Cook et al. 2013a), as well as other researchers (Kamalian et al. 2014; García-Ceja et al. 2015), where a fast release of the probiotic was observed in SIF. This is a new finding and could prove critical for targeting the release of bioactives, such as probiotic bacteria, in the large intestine and developing a novel delivery system using natural polymers. A number of approaches have been investigated to achieve the controlled release of probiotics targeting the colon. In a previous study from our research group, a layer-by-layer approach was developed for coating alginate microcapsules with chitosan, which resulted in the gradual release of the bacterial load in simulated small intestinal fluid over 240 min of exposure (Cook et al. 2013b). This approach could be modified, possibly using blends of coating materials and/or altering the number of coating layers, in order to minimise the dissolution of the microcapsule in the small intestine and ensure release of the load into the large intestine. However, such an approach would be difficult to scale up and commercialise due to the complexity of the layer-by-layer coating process. Another approach was the development of a multi-particulate dosage form to deliver a synbiotic (the combination of a probiotic microorganism and a prebiotic carbohydrate), consisting of poly(d,l-lactic-co-glycolic acid) (PLGA) microcapsules containing the prebiotic which were incorporated into an alginate-chitosan matrix containing the probiotic strain (Cook et al. 2014). The system was able to reduce the release of the probiotic in simulated small intestinal fluid and achieve significant release in simulated proximal colon (the early stage of the large intestine). However, from an industrial perspective, the production of such multi-particulate systems would be rather complicated. The method developed in this study is much simpler compared with the above methods and constitutes an entirely novel approach for the colonic delivery of probiotics to potentially address gastrointestinal disorders including antibiotic-associated diarrhoea, travellers' diarrhoea, irritable bowel syndrome (IBS), irritable bowel disease (IBD), and Crohn's disease.

Considering the results of the faecal batch fermentation experiment, it is likely that the dissolution of the particles observed (Fig. 4) could be due to prolonged incubation leading to the physical erosion of the particles. Moreover, it could be partly due to the activity of enzymes released by microbial constituents of the complex faecal microbiota, which are able to degrade the polymeric components of the particles, i.e. agar or gelatin. Agar can be degraded by agarolytic bacteria isolated primarily from marine environments (Michel and Czjzek 2013); however, there is little information regarding the potential agarolytic activities of human gut bacteria, which are likely to be low. However, a study in nature (Hehemann et al. 2010) demonstrated based on gut metagenome analyses that agarases and porphyranases (enzymes hydrolysing porphyrin, a sulphated carbohydrate derived from red algae) are frequent in the Japanese population and are absent in metagenome data from North American individuals. The authors suggested that as seaweeds make an important contribution to the daily diet in Japan, seaweeds with associated marine bacteria may have been the route by which these carbohydrases were acquired in human gut bacteria (Steck et al. 2011). On the other hand, Gram-positive commensal bacteria present in the 
gastrointestinal tract, in particular Enterococcus faecalis, have been shown to exert gelatinolytic activity (Steck et al. 2011). An additional interesting point is that with the available data, it is difficult to explain why the bacterial loaded particles dissolved faster than the unloaded ones (Fig. 5). One possible explanation could be that $L$. plantarum was able to slowly degrade the agar-gelatin particles; however, in general, lactobacilli do not have gelatinolytic and agarolytic activities; nevertheless, the enzymatic activities of this particular strain need to be studied to verify this. A more likely explanation is that the presence of entrapped bacterial cells within the agargelatin particles changed the structure of the particles, making the polymer matrix less strong, thus leading to faster dissolution. To this end, a more in-depth structural study of the agargelatin particles is needed to understand the dissolution pattern better.

The chitosan-coated agar-gelatin particles were able to protect the cells during incubation for $2 \mathrm{~h}$ in SGF and resist dissolution in SIF during $3 \mathrm{~h}$ of incubation, maintaining also cell viability. An interesting finding of this method used for preparing the particles was autoclaving the mixture of agar and gelatin at $121{ }^{\circ} \mathrm{C}$ for $15 \mathrm{~min}$ to influence on the particles' dissolution properties, as the particles produced without autoclaving dissolved immediately in SGF. The chitosancoated agar-gelatin particles had unique properties, and considering the simple method used for their production, they have a lot of potential to be used as novel formulation devices for the controlled release of probiotics and potentially other solid bioactives in the large intestine.

Author contributions Albadran HA and Monteagudo-Mera A performed the experiments and prepared the manuscript. Khutoryanskiy $\mathrm{V}$ and Charalampopoulos D supervised the work and provided critical revision to the manuscript. All authors have approved the final version. All authors agree to take responsibility for accuracy and integrity of the research.

\section{Compliance with ethical standards}

Conflict of interest The authors declare that they have no conflict of interest.

Ethical approval This study was carried out in duplicate using faecal samples from three different volunteers (one faecal donor for each experimental setup). The study was conducted according to guidelines laid down in the Declaration of Helsinki 1975, as revised in 1983. After obtaining verbal informed consent, a standard questionnaire to collect information regarding the health status, drug use, clinical anamnesis, and lifestyle was administrated before the donor was asked to provide a faecal sample. Ethical approval of collecting faecal samples from healthy volunteers was obtained by the Research Ethics Committee of the University of Reading in 2014.

Open Access This article is licensed under a Creative Commons Attribution 4.0 International License, which permits use, sharing, adaptation, distribution and reproduction in any medium or format, as long as you give appropriate credit to the original author(s) and the source, provide a link to the Creative Commons licence, and indicate if changes were made. The images or other third party material in this article are included in the article's Creative Commons licence, unless indicated otherwise in a credit line to the material. If material is not included in the article's Creative Commons licence and your intended use is not permitted by statutory regulation or exceeds the permitted use, you will need to obtain permission directly from the copyright holder. To view a copy of this licence, visit http://creativecommons.org/licenses/by/4.0/.

\section{References}

Brodsky B, Ramshaw JAM (1997) The collagen triple-helix structure. Matrix Biol 15:545-554. https://doi.org/10.1016/S0945-053X(97)90030-5

Chen L, Ma L, Zhou M, Liu Y, Zhang Y (2014) Effects of pressure on gelatinization of collagen and properties of extracted gelatins. Food Hydrocoll 36:316-322. https://doi.org/10.1016/j.foodhyd.2013.10.012

Cheng M, Deng J, Yang F, Gong Y, Zhao N, Zhang X (2003) Study on physical properties and nerve cell affinity of composite films from chitosan and gelatin solutions. Biomaterials 24:2871-2880. https:// doi.org/10.1016/S0142-9612(03)00117-0

Cho GS, Hanak A, Huch M, Holzapfel WH, Franz CMAP (2010a) Investigation into the potential of Bacteriocinogenic Lactobacillus plantarum BFE 5092 for biopreservation of raw turkey meat. Probiotics Antimicrob Proteins 2:241-249. https://doi.org/10.1007/ s12602-010-9053-4

Cho GS, Huch M, Hanak A, Holzapfel WH, Franz CMAP (2010b) Genetic analysis of the plantaricin EFI locus of Lactobacillus plantarum PCS20 reveals an unusual plantaricin E gene sequence as a result of mutation. Int J Food Microbiol 141:S117-S124. https:// doi.org/10.1016/j.ijfoodmicro.2010.02.022

Cho GS, Krauß S, Huch M, Du Toit M, Franz CMAP (2011) Development of a quantitative PCR for detection of Lactobacillus plantarum starters during wine malolactic fermentation. J Microbiol Biotechnol 21:1280-1286. https://doi.org/10.4014/jmb.1107.07003

Cook MT, Tzortzis G, Charalampopoulos D, Khutoryanskiy VV (2011) Production and evaluation of dry alginate-chitosan microcapsules as an enteric delivery vehicle for probiotic bacteria. Biomacromolecules 12:2834-2840. https://doi.org/10.1021/bm200576h

Cook MT, Tzortzis G, Charalampopoulos D, Khutoryanskiy VV (2012) Microencapsulation of probiotics for gastrointestinal delivery. J Control Release 162:56-67. https://doi.org/10.1016/j.jconrel.2012.06.003

Cook MT, Saratoon T, Tzortzis G, Edwards A, Charalampopoulos D, Khutoryanskiy VV (2013a) CLSM method for the dynamic observation of $\mathrm{pH}$ change within polymer matrices for oral delivery. Biomacromolecules 14:387-393. https://doi.org/10.1021/ bm301569r

Cook MT, Tzortzis G, Khutoryanskiy VV, Charalampopoulos D (2013b) Layer-by-layer coating of alginate matrices with chitosan-alginate for the improved survival and targeted delivery of probiotic bacteria after oral administration. J Mater Chem B 1:52-60. https://doi.org/ $10.1039 / \mathrm{c} 2 \mathrm{tb} 00126 \mathrm{~h}$

Cook MT, Tzortzis G, Charalampopoulos D, Khutoryanskiy VV (2014) Microencapsulation of a synbiotic into PLGA/alginate multiparticulate gels. Int J Pharm 466:400-408. https://doi.org/10. 1016/j.ijpharm.2014.03.034

Duconseille A, Astruc T, Quintana N, Meersman F, Sante-Lhoutellier V (2015) Gelatin structure and composition linked to hard capsule dissolution: a review. Food Hydrocoll 43:360-376. https://doi.org/ 10.1016/j.foodhyd.2014.06.006

FAO/WHO (2002) Guidelines for the evaluation of probiotics in food in report of a joint FAO/WHO. In: Working Group on Drafting Guidelines for the Evaluation of Probiotics in Food, Ontario, C 
García-Ceja A, Mani-López E, Palou E, López-Malo A (2015) Viability during refrigerated storage in selected food products and during simulated gastrointestinal conditions of individual and combined lactobacilli encapsulated in alginate or alginate-chitosan. LWT - Food Sci Technol 63:482-489. https://doi.org/10.1016/j.lwt.2015.03.071

Gómez-Guillén MC, Turnay J, Fernández-Díaz MD, Ulmo N, Lizarbe MA, Montero P (2002) Structural and physical properties of gelatin extracted from different marine species: a comparative study. Food Hydrocoll 16: 25-34. https://doi.org/10.1016/S0268-005X(01)00035-2

Gullapalli RP, Mazzitelli CL (2017) Gelatin and Non-Gelatin Capsule Dosage Forms. J Pharm Sci 106(6):1453-1465

Hehemann JH, Correc G, Barbeyron T, Helbert W, Czjzek M, Michel G (2010) Transfer of carbohydrate-active enzymes from marine bacteria to Japanese gut microbiota. Nature 464:908-U123. https://doi. org/10.1038/nature08937

Honda H, Gibson GR, Farmer S, Keller D, McCartney AL (2011) Use of a continuous culture fermentation system to investigate the effect of GanedenBC30 (Bacillus coagulans GBI-30, 6086) supplementation on pathogen survival in the human gut microbiota. Anaerobe 17:3642. https://doi.org/10.1016/j.anaerobe.2010.12.006

Kamalian N, Mirhosseini H, Mustafa S, Manap MYA (2014) Effect of alginate and chitosan on viability and release behavior of Bifidobacterium pseudocatenulatum G4 in simulated gastrointestinal fluid. Carbohydr Polym 111:700-706. https://doi.org/10.1016/j. carbpol.2014.05.014

Klein D, Janda P, Steinborn R, Müller M, Salmons B, Günzburg WH (1999) Proviral load determination of different feline immunodeficiency virus isolates using real-time polymerase chain reaction: influence of mismatches on quantification. Electrophoresis 20:291299. https://doi.org/10.1002/(SICI)1522-2683(19990201)20: 2<291::AID-ELPS291>3.0.CO;2-R

Krasaekoopt W, Bhandari B, Deeth H (2004) The influence of coating materials on some properties of alginate beads and survivability of microencapsulated probiotic bacteria. Int Dairy J 14:737-743. https://doi.org/10.1016/j.idairyj.2004.01.004

Lam PL, Kok SHL, Ho YW, Wong RSM, Cheng GYM, Cheng CH, Lam KH, Gambari R, Lee KKH, Chui CH (2013) A novel green gelatinagar microencapsulation system with $P$. urinaria as an improved anti-A. niger model. Carbohydr Polym 92:877-880. https://doi. org/10.1016/j.carbpol.2012.09.080

Letendre M, D’Aprano G, Lacroix M, Salmieri S, St-Gelais D (2002) Physicochemical properties and bacterial resistance of biodegradable milk protein films containing agar and pectin. J Agric Food Chem 50:6017-6022. https://doi.org/10.1021/jf011688h

López de Lacey AM, López-Caballero ME, Montero P (2014) Agar films containing green tea extract and probiotic bacteria for extending fish shelf-life. LWT - Food Sci Technol 55:559-564. https://doi.org/10. 1016/j.lwt.2013.09.028

Michel G, Czjzek M (2013) Polysaccharide-degrading enzymes from marine bacteria. In: Trincone A (ed) Marine enzymes for biocatalysis: sources, biocatalytic characteristic and bioprocesses of marine enzymes, Woodhead Publishing Series in Biomedicine pp 429-464
Miller BJ, Franz CMAP, Cho GS, Du Toit M (2011) Expression of the malolactic enzyme gene (mle) from Lactobacillus plantarum under winemaking conditions. Curr Microbiol 62:1682-1688. https://doi. org/10.1007/s00284-011-9914-4

Nualkaekul S, Lenton D, Cook MT, Khutoryanskiy VV, Charalampopoulos D (2012) Chitosan coated alginate beads for the survival of microencapsulated Lactobacillus plantarum in pomegranate juice. Carbohydr Polym 90:1281-1287. https://doi.org/10.1016/j.carbpol.2012.06.073

Phan The D, Debeaufort F, Luu D, Voilley A (2008) Moisture barrier, wetting and mechanical properties of shellac/agar or shellac/cassava starch bilayer bio-membrane for food applications. J Membr Sci 325:277-283. https://doi.org/10.1016/j.memsci.2008.07.052

Prata AS, Grosso CRF (2015) Production of microparticles with gelatin and chitosan. Carbohydr Polym 116:292-299. https://doi.org/10. 1016/j.carbpol.2014.03.056

Sarao LK, Arora M (2017) Probiotics, prebiotics, and microencapsulation: a review. Crit Rev Food Sci Nutr 57:344-371. https://doi.org/ 10.1080/10408398.2014.887055

Saxena A, Kaloti M, Bohidar HB (2011) Rheological properties of binary and ternary protein-polysaccharide co-hydrogels and comparative release kinetics of salbutamol sulphate from their matrices. Int J Biol Macromol 48:263-270. https://doi.org/10.1016/j.ijbiomac.2010.11.008

Steck N, Hoffmann M, Sava IG, Kim SC, Hahne H, Tonkonogy SL, Mair K, Krueger D, Pruteanu M, Shanahan F, Vogelmann R, Schemann M, Kuster B, Sartor RB, Haller D (2011) Enterococcus faecalis metalloprotease compromises epithelial barrier and contributes to intestinal inflammation. Gastroenterology 141:959-971. https:// doi.org/10.1053/j.gastro.2011.05.035

Tian H, Xu G, Yang B, Guo G (2011) Microstructure and mechanical properties of soy protein/agar blend films: Effect of composition and processing methods. J Food Eng 107(1):21-26. https://doi.org/10. 1016/J.JFOODENG.2011.06.008

Wu Y, Geng F, Chang PR, Yu J, Ma X (2009) Effect of agar on the microstructure and performance of potato starch film. Carbohydr Polym 76:299-304. https://doi.org/10.1053/j.gastro.2011.05.035

Yeung TW, Üçok EF, Tiani KA, McClements DJ, Sela DA (2016) Microencapsulation in alginate and chitosan microgels to enhance viability of Bifidobacterium longum for oral delivery. Front Microbiol 7:494. https://doi.org/10.3389/fmicb.2016.00494

Young S, Wong M, Tabata Y, Mikos AG (2005) Gelatin as a delivery vehicle for the controlled release of bioactive molecules. J Control Release 109:256-274

Yucel Falco C, Amadei F, Dhayal SK, Cárdenas M, Tanaka M, Risbo J (2019) Hybrid coating of alginate microbeads based on proteinbiopolymer multilayers for encapsulation of probiotics. Biotechnol Prog 35:1-12. https://doi.org/10.1002/btpr.2806

Zhai M, Zhao L, Yoshii F, Kume T (2004) Study on antibacterial starch/ chitosan blend film formed under the action of irradiation. Carbohydr Polym 57(1):83-88

Publisher's note Springer Nature remains neutral with regard to jurisdictional claims in published maps and institutional affiliations. 